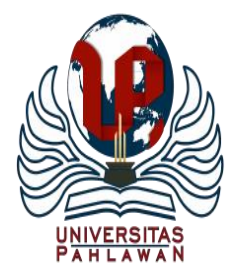

Edukatif : Jurnal Ilmu Pendidikan Volume 2 Nomor 2 Tahun 2020 Halm 158-163

EDUKATIF: JURNAL ILMU PENDIDIKAN

Research \& Learning in Education

https://edukatif.org/index.php/edukatif/index

\title{
Analisis Kebijakan Dan Pengelolaan Pendidikan Dasar terkait Kebijakan Standar Sarana Dan Prasarana Di Sekolah Dasar
}

\author{
Mustika Firdausi ${ }^{1}$, Sufyarma Marsidin ${ }^{2}$, Ahmad Sabandi ${ }^{3}$ \\ Universitas Negeri Padang, Sumatera Barat, Indonesia, ${ }^{1,2,3}$ \\ E-mail : $\underline{\text { mustikafirdausi026@gmail.com }} \underline{\text { sufyarma@gmail.com }}{ }^{2} \underline{\text { sabandi@ @ip.unp.ac.id }}$
}

\begin{abstract}
Abstrak
Artikel ini menganalisis kebijakan dan pengelolaan berdasarkan Peraturan Menteri Pendidikan Nasional Republik Indonesia Nomor 24 Tahun 2007 tentang sarana dan prasarana untuk SD. Penelitian ini dilakukan melalui kajian pustaka. Standar yaitu suatu hal yng sangat penting dalam pendidikan. Suatu penunjang proses merupakan prasarana. Suatu alat yang mendukung pembelajaran saat proses adalah sarana guna untuk menjadikan sekolah tersebut menjadi lancar dalam pembelajaran. Dengan adanya sarana dan prasarana di satuan pendidikan tersebut, maka sekolah tersebut akan menjadi sekolah yang akan selalu diminati semua satuan pendidikan. Karena sarana dan prasarana menggambarkan keefektifan suatu satuan pendidikan.
\end{abstract}

Kata kunci: standar, sarana dan prasarana, sekolah dasar

\begin{abstract}
This article analyzes policies and management based on the Republic of Indonesia's Minister of National Education Regulation No. 24/2007 concerning facilities and infrastructure for elementary schools. This research was conducted through literature review. Standards are a thing that is very important in education. A supporting process is infrastructure. A tool that supports learning during the process is a means to make the school become smooth in learning. With the facilities and infrastructure in the education unit, the school will become a school that will always be in demand by all education units. Because facilities and infrastructure describe the effectiveness of an education unit.
\end{abstract}

Keywords: standards, facilities and infrastructure, elementary schools

Copyright (c) 2020 Mustika Firdausi, Sufyarma Marsidin, Ahmad Sabandi

$\triangle$ Corresponding author :

Address :

Email : mustikafirdausi026@gmail.com

ISSN 2656-8071 (Media Cetak)

Phone :

ISSN 2656-8063 (Media Online)

DOI: $10.31004 /$ edukatif.v2i2.119

Edukatif : Jurnal Ilmu Pendidikan Vol 2 No 2 Tahun 2020 p-ISSN 2656-8063 e-ISSN 2656-8071 
159 Analisis Kebijakan Dan Pengelolaan Pendidikan Dasar terkait Kebijakan Standar Sarana Dan Prasarana Di Sekolah Dasar - Mustika Firdausil, Sufyarma Marsidin2, Ahmad Sabandi

DOI: 10.31004/edukatif.v2i2.119

\section{PENDAHULUAN}

Standar yaitu suatu hal yang sangat penting dalam pendidikan. Dengan standar akan mewujudkan pendidikan yang sangat bermakna. Jadi murid sehingga terlahir manusia yang sangat bertakwa dan sangat positif kepada dan sangat berguna bagi bangsa (Mulyasa, 2009: 39). Ada 8 standar yang ada yaitu standar isi, proses, penilaian, kompetensi kelulusan, pendidik dan tenaga kependidikan, sarpras, pembiayaan, dan pengelolaan. Instrumen tersebut harus wajib ada dalam pendidikan karena sangat penting menunjang proses pembelajaran. Sarana yaitu perlengkapan untuk capai tujuan. Prasarana adalah perangkat dalam proses pembelaran dengan lancar dan tepat (Zafar, 2019).

Di dalam sekolah harus ada beberapa perlengkapan yang harus mendukung proses pembelajaran yaitu beberapa ruang kelas, ruang operator, perpustakaan laboratorium, dan banyak yang lain lagi. Suatu penunjang proses merupakan prasarana. Suatu alat yang mendukung pembelajaran saat proses adalah sarana guna untuk menjadikan sekolah tersebut menjadi lancar dalam pembelajaran (Setyaningih, 2018).

Prasarana yaitu suatu lokasi-lokasi, ruangan, dan bangunan/gedung. Kalau sarana berarti tempat kelas, buku dan lain lain (Sutisna, 1985). Sarpras yaitu suatu rancangan untuk akademik yang berjalan lancar dengan fasilitas yang dimiliki (Saidah, 2019). Sarpras ini merupakan penunjang bagi satuan pendidikan dan hasil belajar serta aktivitas siswa dipengaruhi oleh sarpras ini. Dengan sarpras yang lengkap dan pembelajaran akan semakin membuat peserta didik semakin betah dalam kelas dan semakin mudah peserta didik untuk mempelajari suatu pembelajaran dengan sangat mudah dan gampang serta sangat menyenangkan apalagi jika dimasukkan beberapa metode atau model-model yang unik maka peserta didik akan cepat mempelajari atau menghafal pembelajaran yang materinya sangat banyak (Megasari, 2014).

Penyebab hasil belajar rendah juga karena sarprasnya tidak lengkap. Dari kelengkapan belajar seperti papan yang rusak, kursi yang rusak akan mengganggu proses pembelajaran anak serta akan membuat anak tersebut menjadi gelisah dalam pembelajaran. Alat yang rusak berat juga dapat dimusnahkan atau penghapusan barang yang dilakukan pada setiap tahun dalam penggunaan aset negara. Dan setiap perlengkapan yang dibeli akan dimasukkan dalam daftar aset negara.

Standar sarana dan prasarana ini sangat dibutuhkan dalam penunjang pembelajaran, karena jika sarana dan prasarana di suatu sekolah sangat baik dan lengkap maka akan menjadikan sekolah tersebut menjadi sekolah yang sangat diminati semua orang. Sarpras tersebut dibahas dalam makalah ini. Berdasarkan penjelasan diatas maka makalah ini akan membahas tentang kebijakan standar sarpras di SD.

\section{METODE PENELITIAN}

Tulisan ini menggunakan studi kepustakaan (library research) sebagai metode penelitiannya. Studi kepustakaan identik dengan pengumpulan data dari berbagai sumber bacaan. Buku, jurnal, maupun artikel ,merupakan bahan bacaan yang menjadi sumber data dalam penelitian ini. 


\section{HASIL DAN PEMBAHASAN PENELITIAN}

\section{Pengertian Standar Sarpras}

Suatu penunjang proses merupakan prasarana. Suatu alat yang mendukung pembelajaran saat proses adalah sarana guna untuk menjadikan sekolah tersebut menjadi lancer dalam pembelajaran (Setyaningih, 2018).

Sarana yaitu perlengkapan untuk capai tujuan. Prasarana adalah perangkat dalam proses pembelaran dengan lancar dan tepat (Zafar, 2019). Perlunya sarpras di sekolah yaitu sesuatu untuk di kembangkan pada pendidikan. Karena sangat penting untuk berjalan lancarnya proses pembelajaran. Agar sekolah tersebut menjadi bermakna dalam pembelajaran. Proses pengembangan sarpras di sekolah harus ada manajemen. Dalam upaya pengadaan dan pendayagunaan sarpras di satuan pendidikan diperlukan proses manejmen, yaitu rancangan atau perencanaan, pengadaan, pengaturan, penggunaan, dan penghapusan (Indrawan, 2015).

Semua perlengkapan yang digunakan dalam pembelajaran yang tidak berjalan dan berjalan agar mencapai pembelajaran yang baik yang dinamakan sarana dan perlengkapan yang sebagai pendukung pembelajaran seperti lahan, dan jalan sekolah (Novita, 2017).

Ada 2 prasarana seperti gedung satuan pendidikan serta perlengkapan satuan pendidikan. Gedung satuan pendidikan terdiri dari tempat materi, tempat administrasi, tempat perpustakaan, lingkungan. Perlengkapan satuan pendidikan yaitu yang ada untuk tempat kelas (Ellong, 2007).

Prasarana yaitu suatu lokasi-lokasi ruangan, dan bangunan/gedung. Kalau sarana berarti tempat kelas, buku dan lain lain (Sutisna, 1985). Sarpras yaitu suatu rancangan untuk akademik yang berjalan lancar dengan fasilitas yang dimiliki (Saidah, 2019). Dengan adanya sarpras maka sekolah tersebut dikatakan maju dan sekolah tersebut adalah sekolah yang maju karena mampu memiliki sarpras yang lengkap. Sarpras merupakan kelengkapan untuk mempengaruhi keterampilan peserta didik dalam satuan. Pendidikan untuk instruktur luar dan infrastruktur dalam secara kondisi yang nyata dan kondisi yang negeri maupun swasta satuan pendidikanya untuk meningkatkan pembelajaran (Kartika, 2019).

\section{Bentuk Sarpras}

Bentuk sarana yaitu ada 3 (Novita, 2017):

1. Alat yang lambat habis dan cepat habis Sarana tersebut bisa habis digunakan dan tidak habis digunakan.

a. Alat yang habis secara cepat yaitu seperti kapur putih, spidol dan bahan kimia. Alat yang bisa berubah yaitu kayu, besi, dan karton. Alat yang harus dperlukan pada pembelajaran seperti laptop, lampu, dan buku.

b. Alat yang habisnya dalam waktu lambat seperti kursi, menja, peta dan beberapa perlengkapan dilapangan.

2. Bergerak tidaknya pada saat digunakan;

a. Alat yang bisa digerakkan seperti lemari, dan kursi serta meja.

b. Alat yang tidak bisa digerakkan seperti listrik dan air. 
161 Analisis Kebijakan Dan Pengelolaan Pendidikan Dasar terkait Kebijakan Standar Sarana Dan Prasarana Di Sekolah Dasar-Mustika Firdausil, Sufyarma Marsidin2, Ahmad Sabandi

DOI: 10.31004/edukatif.v2i2.119

3. Hubungannya dengan proses belajar mengajar. Seperti alat pembelajaran, alat peraga, dan sarana pengajaran.

a. Peralatan pembelajaran digunakan langsung seperti alat tulis buku, dan praktek.

b. Alat peraga yaitu alat untuk menolong pembelajaran seperti apersepsi nyata dan tidak nyata.

c. Media pengajaran yaitu membantu mengejar pembelajaran Ada 3 bentuk sarana, yaitu sarana suara, sarana gambar, dan sarana suara dan gambar.

Dan ada jenis prasarana di sekolah seperti: 1) ada prasarana dimanfaatkan untuk pelaksanaan pembelajaran yaitu tempat teori, tempat pustakaan, tempat praktek ketrampilan, dantempat labor. 2) ada prasaranaa yang tempatnya bukan dimanfaatkan untuk pelasanaan pembelajaran namun sebagai pembantu pembelajaran seperti tempat kepsek, ruang makan/kantin, akses tanahdanjalan menuju sekolah, kamar kecil, ruang usaha kesehatan sekolah, ruang guru, ruang kepala sekolah, dan parkiran. Sekolah minimal memiliki prasaranaa sebagai berikut: tempat belajar, tempat pustaka, tempat labor, tempat kepala sekolah, tempat majelis guru, tempat TU, ruang sholat, tempat BK, tempat kesehatan, wc, tempat penyimpanan, tempat udara, ruang olahraga (Novita, 2017).

Adapun ruang/tempat, dari fungsinyaa, yaitu: (a) tempat didikan; (b) tempat administrai; (c) tempat penunjang (d) tempat alat dan media pendidikan; (e) tempat pembuku atau bahan-bahan ajar; (f) sarana dan prasaran pendidikan (Kartika, 2019)

Dari yang diatas maka dapat disimpulkan bahwa ada bentuk-bentuk sarana dan prasarana seperti alat tulis, tempat, bangunan, tempat membaca buku, tempat belajar, tempat rapat, tempat TU, labor, kantin dan lain-lain. Jika semua lengkap maka akan menjadi sekolah yang selalu diminati semua orang, dan menarik perhatian orang-orang tersebut untuk memasukkan anakanaknya ke skolah tersebut, karena mutu dan kualitas sekolah juga di dasari oleh fasilitas dan kelengkapan sekolah baik untuk dalam kelas maupun luar kelas.

\section{Tujuan Sarpras}

Tujuan sarpras yaitu (Parid, 2020) 1) supaya dapat penyediaan fasilitas dan alat dengn cara persiapan dan penyediaan yang tersusun, 2) mengupayakan pengaplikasian fasilitas dan alat sekolah dengan efektif, 3) supaya membantu tanggungan siap operasi fasilitas untuk membantu mulusnya kerja dengan demikian dapat akhir yang bagus, 4) supaya mengupayakan pelestarian fasilitas dan alat dengan demikian bantuk dalam keadaan bisa digunakan dikala diperlukan untuk orang di pendidikan.

Tujuan lain dari (Ellong, 2007) yaitu untuk memperindah ruangan, tempat dan segala yang bergerak dan tidak bergerak agar tujuan pembelajaran menjadi sangat tepat dan prosesnya menjadi nyaman dan efisien buat belajar di kelas dan dipandang orang.

Dari yang diatas dapat simpulkan bahwa tujuan sarpras ini adalah untuk membuat warga 
162 Analisis Kebijakan Dan Pengelolaan Pendidikan Dasar terkait Kebijakan Standar Sarana Dan Prasarana Di Sekolah Dasar - Mustika Firdausil, Sufyarma Marsidin2, Ahmad Sabandi

DOI: 10.31004/edukatif.v2i2.119

sekolah tertarik buat belajar dengan semangat dan belajar dengan nyaman dalam kelas karena di dalam kelas sudah terdapat fasilitas yang dipeerlukan dan di luar kelas sudah ada beberapa taman dan tanah yang luas buat anak-anak dalam melakukan kegiatan bermain dan olahraga serta tempat parkiran dan bangunan-bangunan lainnya dan peralatan yang mendukung pembelajaran perlengkapan media, alat tulis dan lain-lain.

Tujuan lainnya yaitu untuk memperkuat daya ingat peserta didik, keterampilannya serta hafalannya sangat berpengaruh dengan sarpras yang digunakan dalam satuan pendidikan tersebut. Oleh karena itu kepala sekolah harus bisa melengkapinya dengan sangat baik dan memilih kelengkapan harus pintar dan warga sekolah harus bisa merawat dan menjaga sarpras yang sudah ada, agar tidak menjadi rusak berat dalam penggunaannya.

\section{RuangLingkup Sarpras}

Ruang lingkup sarpras yaitu (Parid, 2020):

1. Rancangan

Didalam rancangan harus ada menentukan arahan pertama perihal kebutuhan sekolah, menetapkan kebutuhan sekolah serupa bentuk rakyat dan lain lain.

2. Penyediaan

Di dalam penyediaan dilakukan oleh semua yang ada di sekolah.

3. Inventaris

Inventaris yaitu untuk memberikan tanda benda, kata benda, asal benda, banyak benda, kapan beli benda, pergantian benda, asal uang dan lain lain.
4. Pelestarian

Pelestarian digunakan untuk bisa menjaga benda supaya terawat. Pelestarian atau perawatan dilakukan dengan berbagai cara oleh semua warga sekolah agar tidak rusak, tidak susut dan tetap rapi dengan cara seharihari dan berkala (Saidah, 2019).

5. Penghilangan

Penghilangan benda jika benda tersebut sudah tidak layak pakai atau rusak berat, ekspayer sudah lewat.

Di sisi lain (Ellong, 2007) planning yaitu sesuatu yang diadakan dimasa datang. Dilihat dari warga sekolah dulu. Syarat-syaratnya adalah (1) mencontoh standar bentuk, mutu, kapasitas sarpras skala utama (2) memperbanyak kelengkapan yang dibutuhkan (3) mempersiapkan dan memakai sarpas operasional (4) menyimpan dan (5) ikuti prosedur pengelolaan (6) planning perbanyak barang yang dapat berjalan (7) planning habis digunakan dan tidak habis digunakan (8) planning perbanyak barang yang berjalan habis digunakan (9) planning perbanyak tidak berjalan (10) hitungan untuk keperluangan pembelajaran.

Pemeliharaan terhadap barang sangatlah harus dilakukan dari waktu ke waktu agar barang tersebut tidak rusak dan tetap rapi serta bersih (Nasruddin, 2018). Guru berperan pada sarpras yaitu planning, manfaanya, memelihara dan mengawasi sarpras tersebut (Rahmawati, 2019).

\section{KESIMPULAN}

Di dalam sekolah harus ada beberapa perlengkapan yang harus mendukung proses pembelajaran yaitu beberapa ruang kelas, ruang 
163 Analisis Kebijakan Dan Pengelolaan Pendidikan Dasar terkait Kebijakan Standar Sarana Dan Prasarana Di Sekolah Dasar - Mustika Firdausi1, Sufyarma Marsidin2, Ahmad Sabandi

DOI: 10.31004/edukatif.v2i2.119

operator, perpustakaan laboratorium, dan banyak yang lain lagi. Suatu penunjang proses merupakan prasarana. Suatu alat yang mendukung pembelajaran saat proses adalah sarana guna untuk menjadikan sekolah tersebut menjadi lancar dalam pembelajaran (Setyaningih, 2018).

Sekolah minimal memiliki prasaranaa sebagai berikut: tempat belajar, tempat pustaka, tempat labor, tempat kepala sekolah, tempat majelis guru, tempat $\mathrm{TU}$, ruang sholat, tempat $\mathrm{BK}$, tempat kesehatan, wc, tempat penyimpanan, tempat udara, ruang olahraga.

Jadi sarana dan prasarana di setiap sekolah sangat penting supaya berjalannya pembelajaran yang sangat bermakna dan setiap peserta didik merasa sangat nyaman satuan pendidikan tersebut. Serta hasil belajar sangat dipengaruhi oleh kelengkapan sarpras pada sekolah tersebut, serta sistem belajar pun juga menjadi unik dan menyenangkan jika sarana tersebut lengkap.

\section{DAFTAR PUSTAKA}

Ellong, T. D. A. (2007). Manajemen Sarana Dan Prasarana Di Lembaga Pendidikan Islam. Pendidikan Islam Iqra', 11(1), 1-8.

Indrawan, I. (2015). Pengantar Manajemen Sarana dan Prasarana Sekolah. Deepublish.

Kartika, S. (2019). Pengaruh Kualitas Sarana dan Prasarana terhadap Minat Belajar Siswa dalam Pembelajaran Pendidikan Agama Islam. 7(1).

Megasari, R. (2014). Peningkatan Pengelolaan Sarana dan Prasarana Pendidikan Untuk Meningkatkan Kualitas Pembelajaran Di SMPN 5 Bukittinggi. Jurnal Administrasi Pendidikan, 2(1), 636-831.
Prasarana Pendidikan Dalam Proses Pembelajaran Di SD Negeri Ngrukeman Tamantirto Kaihan Bantul.

Novita, M. (2017). Sarana Dan Prasarana Yang Baik Menjadi Bagian Ujung Tombak Keberhasilan Lembaga Pendidikan Islam. NUR EL-ISLAM: Jurnal Pendidikan Dan Sosial Keagamaan, Volume 4,(2), 127. http://ejournal.staiyasnibungo.ac.id/index.php /nurelislam\%0Ahttp://moraref.or.id/record/vi ew/64714

Parid, M. \& A. L. S. A. (2020). Pengelolaan Sarana dan Prasarana Pendidikan. Jurnal Tafhim Al-Ilmi, 11(2), 266-275.

Rahmawati, M. (2019). Pengertian Administrasi Sarana dan Prasarana. 1-3.

Saidah, N. (2019). Pengertian, Proses Administrasi Sarana dan Prasarana.

Setyaningih, S. (2018). Pengelolaan sarana prasarana dalam implementasi kurikulum pendidikan guru sekolah dasar: Sebuah studi kasus di Universitas Negeri Semarang. Jurnal Managemen Pendidikan, 13(1), 6271. https://doi.org/10.23917/jmp.v13i2.6397

Sutisna, O. (1985). Administrasi Pendidikan: Dasar Teoritis untuk Praktek Profesional. Angkasa.

Zafar, M. A. \& H. A. (2019). Administrasi Sarana dan Prasarana. Jurnal Administrasi Sarana Dan Prasarana, $1,4$.

Nasruddin. (2018). Manajemen Sarana dan 